\title{
Research on Developing Situation of Construction Industry in Sichuan Province
}

\author{
Yuliang Fan ${ }^{1, a}$, Fenghui Chen ${ }^{1, b}{ }^{*}$ and Qiong Shen ${ }^{2, c}$ \\ ${ }^{1}$ College of Civil Engineering, Sichuan Agricultural University, Dujiangyan, China \\ ${ }^{2}$ College of Architecture and Urban-Rural Planning, Sichuan Agricultural University, Dujiangyan, \\ China \\ afylsicau@126.com, bcfenghui@sicau.edu.cn, c727202860@qq.com
}

Keywords: Construction industry; Absolute difference; Difference coefficient; Gini coefficient

\begin{abstract}
The aim of this paper is to understand the developing situation of the construction industry in Sichuan province. In this study, the annual construction industry output and labor productivity of 21 cities in Sichuan province were chosen as basic indicators from 2004 to 2014 . Based on the two indicators, the absolute difference and difference coefficient were calculated to reflect to time and space change of the development of the construction industry in Sichuan province, while the Gini coefficient of construction industry in Sichuan province was calculated to evaluate the overall developing situation of the construction industry. The results show that the absolute difference and the difference coefficient in the study period were increasing year by year, but in the later, the increase of them has slowed down. The overall development of the construction industry in Sichuan province is in the stage of growth convergence and difference maintenance in Williamson converse- $U$ curve, the construction industry takes on area-aggregation phenomenon. The results indicate that the overall development of the construction industry in Sichuan province is not balance.
\end{abstract}

\section{Introduction}

Sichuan province is located in Southwest China, with an area of 486,000 square kilometers, covering 21 cities. In 2014, the construction industry output reached 814.852 billion Yuan, which was 6 times more than that of 2004 [1]. However, due to the reasons of natural geographical regions [1], economic level [2], infrastructure, policy differences [3] the construction industry ether in terms of scale, or in terms of quality, it is obvious of its regional differences and imbalances of development of construction [4]. In view of the importance of construction industry to promote economic growth and promote domestic consumption [5], it is necessary to study the development of the construction industry in Sichuan province, furtherly. At present, there are several analytical methods for the development of the construction industry, such as factor analysis [6], cluster analysis method [7], grey model and time series analysis method [8], the method of spatial econometrics [9], regional economic growth trend and economic difference analysis method [10], and so on. In recent years, the majority of scholars have pay attention to regional economic growth trend and economic difference analysis method, which can find out relevant elements of the regional development differences and the status quo of the construction industry. In different regions, the method has been widely used [11].

In this study, the annual construction industry output and labor productivity of 21 cities in Sichuan province were selected as basic indicators to calculate the absolute difference and difference coefficient and the Gini coefficient of overall construction industry from 2004 to 2014. The object of the study is to evaluate the development status of construction industry in Sichuan province. 


\section{Research Method}

Research scheme. First of all, the absolute difference and difference coefficient were calculated based on the annual construction industry output and labor productivity of 21 cities in Sichuan province from 2004 to 2014, and their differences were analyzed. Then, the proportion of each city's construction industry output accounted for in the total amount of the whole province, was calculated from 2004 to 2014, respectively. At last, the Gini coefficient of construction industry in Sichuan province from 2004 to 2014 was calculated to evaluate the development status of the construction industry in Sichuan Province.

Data selection and source. Two basic indicators (i.e., the annual data of construction industry output and labor productivity) of 21 cities in Sichuan province from 2004 to 2014 were used in this study. The data of the two basic indicators were obtained from Sichuan Statistical Yearbook (2005-2015).

The calculation of absolute difference and difference coefficient. The absolute difference and difference coefficient of the two basic indicators were calculated in each year from 2004 to 2014. The specific calculating methods of the absolute difference and difference coefficient were shown as the following equations (1) and (2).

Absolute difference: $\Delta \mathrm{X}=\mathrm{X}_{\max }-\mathrm{X}_{\min }$

there, $\mathrm{X}_{\min }$ and $\mathrm{X}_{\max }$, respectively, represents the maximum and minimum of construction industry output and labor productivity of 21 cities in Sichuan province.

Difference coefficient: $C V=\frac{\sqrt{\sum_{i=1}^{n} \frac{(X i \quad \bar{X})^{2}}{n}}}{\bar{X}}$

there, $\bar{X}=\frac{1}{n} \sum_{i=1}^{n} X_{i}, X_{i}$ represents the annual construction industry output and labor productivity of $i$ th city in Sichuan province. $\mathrm{n}=21$.

The calculation of Gini coefficient of construction industry. The Gini coefficient equation of construction industry in Sichuan province from 2004 to 2014 is as follows:

$$
\mathrm{Gi}=\frac{1}{2 \mathrm{n}^{2} \overline{\mathrm{sk}}} \sum_{\mathrm{i}=1}^{\mathrm{n}} \sum_{\mathrm{j}=1}^{\mathrm{n}}\left|\mathrm{SK}_{\mathrm{i}}-\mathrm{SK}_{\mathrm{j}}\right|
$$

there, $s \mathrm{k}_{\mathrm{i}}$ and $\mathrm{sk}_{\mathrm{j}}$ represents the proportion of $i$ th and $j$ th city's construction industry output accounted for in the total amount of the whole province, each year respectively. $n=21$, and $\overline{s k}$ is the average of 21 cities' construction industry output accounted for in the total amount of the whole province.

\section{Results and Discussion}

Absolute difference and difference coefficient. Fig. 1 shows the absolute difference and different coefficient of construction industry and labor productivity in Sichuan province from 2004 to 2014. In the study period, the annual absolute difference (Fig. 1 (a)) of construction difference was large in Sichuan province. The increase velocity of absolute difference of construction industry output tended to decrease until 2013.The absolute difference of labor productivity of construction industry (Fig. 1 (b)) in Sichuan province increased for two years from 2004, and it descended from 2006 to 2010, firstly. Then it increased for two years rapidly, and it decreased in 2013. At last, it increased in 2014, but it was slightly lower than the high peaks of the absolute difference of labor productivity of construction industry in 2012. Although the absolute difference fluctuated, the increasing tendency in recent years was convergence. The results are related to the free flow of various factors affecting the development of the construction industry in the different regions [12]. With the uneven distribution of the factors of construction production, the construction industry gap in Sichuan province gradually was revealed. In the study period, the difference coefficient of construction industry output (CV1) and labor productivity (CV2) (Fig. 1(c)) tended to ascend firstly from 2004 
to 2006, but limited, the fluctuation was more stable. Then it tended to decrease from 2007 to 2010 . At last, it increased in 2011 and then descended from 2012 to 2014. The results show that the development of construction industry in Sichuan province underwent a complex processes that the development gap among 21 cities experienced twice expansion-to-reduction stages [13]. The reason of the results is might be caused by the western development of China [14]. The results indicate that the construction industry development situation in Sichuan province is in the left of converse-U curve, which conforms to the economic phenomena of converse- $U$ theory [15].
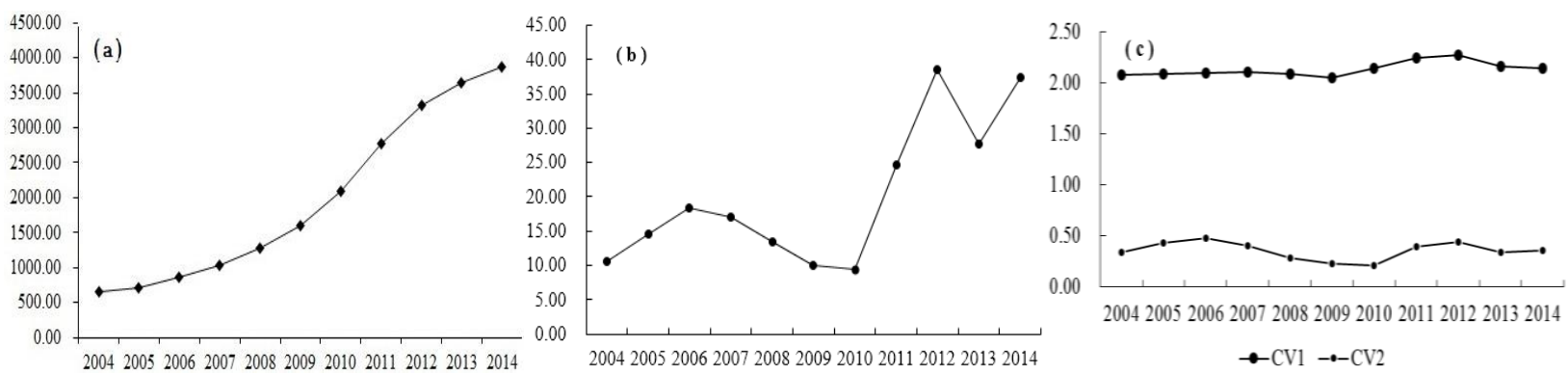

Figure 1 Absolute difference and difference coefficient of construction industry output and labor productivity in Sichuan Province from 2004 to 2014. (a) absolute difference of construction industry output, (b) absolute difference of labor productivity, and (c) absolute difference and difference coefficient of construction industry output (CV1) and labor productivity (CV2).

Gini coefficient of construction industry. Fig. 2 shows the variation of Gini coefficient of construction industry in Sichuan province from 2004 to 2014. According to the numerical division of Gini coefficient, the more the distribution of construction industry of different regions is uniform, the less the Gini coefficient. Thus the Gini coefficient is zero when the distribution of the construction industry in all the regions is equal, while the Gini coefficient is approach to 1 when the construction industry concentrated in a region. In Fig. 2, the minimum of Gini coefficient of construction industry in Sichuan province is 0.61 . It shows that the wide gap exists among the 21 cities in Sichuan province [16]. The results indicate that the development of construction industry in Sichuan province is not balance in the study period, and it has an aggregation tendency in 21 cities.

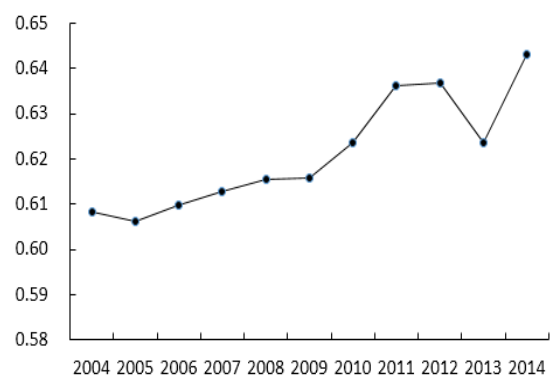

Figure 2 The Gini coefficient of construction industry in Sichuan province from 2004 to 2014

\section{Conclusion}

The study selected two basic indicators (i.e., the annual construction industry output and labor productivity) of 21 cities in Sichuan province from 2004 to 2014 to reveal the development status of construction industry in Sichuan province through the analysis of the absolute difference and difference coefficient and Gini coefficient. The results show that the absolute difference and difference coefficient of construction industry and labor productivity in Sichuan province was increasing year by year, but the growth trend has slowed down in recent years. The overall development of the construction industry in Sichuan province is in the stage of the growth convergence and difference maintenance in the Williamson converse- $U$ curve. The study indicates 
the overall development of construction industry is not balance. In Sichuan province, the different policies and measures for 21 cities should be proposed according to the features of region and nationality to promote the development of construction industry.

\section{References}

[1] Sichuan Provincial Bureau of Statistics in China: Sichuan Statistical Yearbook (China Statistics Press, China 2015).

[2] F.J. Zhang: Regional Differences of China 's Urbanization and Its Economic Basis (Northwest University, China 2014)

[3] G.T. Qiu: Social Sciences in China Vol.34 (2013), p.4-21.

[4] J. Li: Knowledge Economy Vol.11 (2009), p.50.

[5] C.S. Sun, Y.W. Wang and Y. Chang: Construction Economy Vol.31 (2010), p.15-17.

[6] C. Zhuang, and J.R. Ye: Knowledge Economy Vol.14 (2012), p.127.

[7] Y.J. Li, H.Y. Liu and S.Y. Hao: Journal of Civil Engineering and Management Vol.16 (2014), p.78-83.

[8] J.J. Tang, Z.X. Li and W.Z. Liang: Journal of Civil Engineering and Management Vol.14 (2012), p.84-88.

[9] M. Zhang, D.Y. Qiao and Y.A. Dai: Scientific Decision-Making Vol.16, p.87-93.

[10] B. Wen, Y.S. Wang and Y. Zhang: Construction Economy Vol.30 (2009), p.9-12.

[11] C.Y. Zeng: Guide To Business Vol.14 (2013), p.81-82.

[12] X.S. Shi, and S.D. Zhao: Journal of Quantitative \& Technical Economics Vol.28 (2011), p.51-62.

[13] S.Y. Zhang, and Z.Y. Ren: Economic Geography Vol.31 (2011), p.903-909.

[14] W.Y. Gan, X.X. Xu and J. Yi, Economic Geography Vol.31 (2011), p.40-46.

[15] M.Z. Qian: Journal of World Economy Vol.30 (2007), p.56-63.

[16]Information on http://intl.ce.cn/zhuanti/data/jini/jinidata/201001/07/t20100107_20760807.shtml 